\section{THE EXISTENCE OF A MAGNETIC SENSE.}

Since the day when Thales, about twenty-four hundred years ago, rubbed a piece of amber on silk and found that it attracted light particles, the phenomena of magnetic action have been regarded with feelings of awe and mystery. The strange entrancing of animals brought about by an intense fixation of their gaze was referred to ' animal magnetism,' because nobody understood either the one or the other. The discovery of the magnetic needle, and its mysterious constant pointing towards the north, added another element to the wonders of magnetism. Mesmer was keen enough to see, that, by explaining the hypnotic phenomena to which he gave his name as due to 'magnetism,' he was treading on safe ground. That elastic cabinet of mysteries could easily be made to accommodate another series of peculiar facts, and the theory had thenceforth a habitation and a name. The mere mention of socalled magnetic cures is sufficient to suggest a host of alleged facts and wonders. Although all such phenomena assume that the human body is susceptible to the influence of the magnetic field, Baron Reichenbach, in a series of experiments since become famous, was the first to attempt a scientific proof of such an influence. He thus described his 'sensitives,' who were variously affected by the presence of a magnetic field: some saw flames issuing from the poles; some had disagreeable organic sensations; some were benefited by it; and so on. These experiments were repeated by Professor Barrett of the English Society for psychical research, but altogether with negative results, until the young men who had done such good service in the thought-transferrence department were called in to describe the effects of a magnetic field upon them. They saw the lights issuing from the poles, and felt the pains in the temples when very near the magnet. Before these experiments, Sir William Thomson had expressed the opinion that it would certainly be strange if no magnetic sense existed. The fact that nothing happened when he put his head between the poles of a powerful magnet, he regards as very wonderful. Finally, French observers have recorded the fact that hypnotics who have responded to the suggestion that one-half of the body is affected in a certain way (e.g., one arm is insensitive) will have the affection transferred to the other side of the body, and removed from the first side (i.e., the other arm will become insensitive), by the application of a magnet on the opposite side of the body.

The above hasty sketch of what has been done towards solving the question of the possible effect of a magnet on human nerves seems to suggest that a rigid scientific test upon normal persons is highly desirable. It was to supply this want that the experiments about to be described were undertaken. ${ }^{1}$ The special points which were borne in mind were, $1^{\circ}$, to exclude the action of chance; and, $2^{\circ}$, to rule out all possible modes of suggestion as to what was going on. We believe that we accomplished these objects by using the following method and apparatus. A large and powerful electro-magnet was tipped on its side and supported between two tables. The head of the person to be tested (to be called 'the subject') was placed between the poles of the magnet, with the forehead and back of the head all but touching the poles. He was seated upright in a chair, with his head in a normal and fairly comfortable position. The magnet and the subject were on the third floor of the building. In the room on the ground-floor there was a dynamo-machine, which, when turned by the operator, generated the current. The magnet was connected with the dynamo by heavy insulated wires passing out of the windows and along the wall of the building. The subject and the operator communicated by a system of telegraphic signals : otherwise they were completely isolated from one another.

At the first stage of the experiments the following method was employed. After the operator had received the signal that the subject was ready, he did one of two things: 1 . He turned the current on, and when, after a short interval, the subject signalled ' Change,' he turned it off, turning it on again when the second 'change' was signalled; 2 . He began by doing nothing, turned the current on at the first 'change,' and off at the second. In either case he received a signal from the subject when the observation was concluded. In each observation the subject knew that the condition of the magnet at the beginning and at the end of the experiment was the same, but that in the middle, between the two ' changes,' the time of which he himself directed, the condition was different. His object was to tell whether the magnet was on or off at that intermediate time. His opportunities for judging were extremely favorable, for he knew exactly when to expect the sensation of a change from one condition to another; and he knew that in one case it would be change from magnetization to demagnetization, and in the other case a reverse change. He had simply to tell which was which. It is evident that by mere guesswork he would answer correctly one-half the time,

1 The experiments were conducted in the psycho-physical laboratory of the Johns Hopkins university. Dr. G. H. F. Nuttall was associated with me in the work. 
for he had only a choice between two things, one of which was right and the other wrong. The number of correct answers above one-half the total number of answers would measure the magnetic sensibility.

Experimenting in this way, we were surprised to find that considerably more than one-half the answers were correct. Apparently the magnetic sense was there. But it was soon observed that we more or less consciously judged by the sound that the turning of the dynamo transmitted along the wire, and thus to the magnet. When the attention was once directed to this point, the doings of the operator could be correctly told every time. After many failures, we succeeded in eliminating this sound by cutting the wires, and inserting one end of each into a mercury-cup, and connecting the other by a binding-screw with the cup. The wires were suspended from the ceiling by silk threads, and inserted freely in the mercury: in this way the sound-vibrations were transmitted to the mercury, and only very weakly taken up again by the wire. This arrangement was inserted in the circuit once in the basement room, and again on the sill of the window, as the wires passed the second floor of the building. The turning of the dynamo was thus rendered inaudible; and for a time the results were negative, the number of correct answers being just about one-half of the total number of experiments. But soon the correct answers became more and more frequent. This time the indications were more subtle. As is well known to physicists, the magnetization and demagnetization of a powerful magnet produce a molecular crepitation throughout its mass, which gives rise to a very faint but audible click. It was this click, and not the magnetic sense, that told us when the current was being turned on, and when off. It is remarkable that we used this click as an indication of the condition of the magnet long before we were distinctly conscious of its existence. This click could not be heard every time, but, with the attention sharply focused, almost every time. But it will be objected, as the click accompanied each 'change,' it could not guide the judgment of the subject. This objection would hold were it not that the click accompanying demagnetization is much more pronounced than that accompanying magnetization. In fact, the latter could rarely, if ever, be distinctly heard.

These difficulties were obviated by a slight alteration in the mode of experimentation. At the beginning of each experiment the current was off ; at the signal of 'Change,' the current was either turned on or left off. The subject had then simply to decide whether, on the whole, something had been going on during the experiment, or whether the dynamo had not been turned at all. In this way, only the magnetization, and never the demagnetization, occurred in the experiments, and the click was thus avoided. Moreover, to completely guard against the very slight click of magnetization, the current was not made as formerly, by the closing of a key; but, with a key always closed, the dynamo was turned with gradually increasing speed. It is the suddenness of the magnetization that produces the click. It is evident, that, as before, the chances of a correct guess are just onehalf. The opportunities for judging are perhaps not as favorable when only one change is made, but it is doubtful whether even this difference is appreciable. It is this latter method that was used throughout the rest of the experiments. In all, ten persons, all students in good health, were experimented upon, including Dr. Nuttall and the writer. The results are given in the following table :-

\begin{tabular}{|c|c|c|c|c|}
\hline Subject. & $\begin{array}{l}\text { No. of } \\
\text { experi- } \\
\text { ments. }\end{array}$ & $\begin{array}{c}\text { No. of } \\
\text { correct } \\
\text { answers. }\end{array}$ & $\begin{array}{c}\text { No. of correct } \\
\text { answers by } \\
\text { the action of } \\
\text { chance. }\end{array}$ & $\begin{array}{l}\text { Diver- } \\
\text { gence. }\end{array}$ \\
\hline 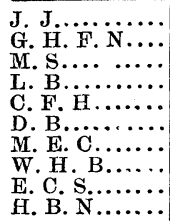 & $\begin{array}{l}550 \\
550 \\
150 \\
100 \\
100 \\
100 \\
100 \\
100 \\
100 \\
100\end{array}$ & $\begin{array}{r}286 \\
287 \\
76 \\
50 \\
47 \\
47 \\
44 \\
53 \\
51 \\
50\end{array}$ & $\begin{array}{r}275 \\
275 \\
75 \\
50 \\
50 \\
50 \\
50 \\
50 \\
50 \\
50\end{array}$ & $\begin{array}{l}+11 \\
+12 \\
+\quad 1 \\
-\quad 3 \\
-\quad 3 \\
=6 \\
+\quad 3 \\
+\quad 1 \\
0\end{array}$ \\
\hline
\end{tabular}

This table makes it evident, that, in the case of those experimented upon, no sensibility for a magnetic field existed. This still leaves the question open, whether there may not be a morbid sensibility for such an effect; but it makes such a possibility less probable, because the sensibility for a magnetic field ascribed to 'sensitives' is so intense, that some slight remnant of it might be expected to exist in normal persons. It was intended to test persons who were good hypnotic subjects both in the normal and the hypnotic conditions, but no opportunity offered itself. Our conclusions refer only to the question of a normal magnetic sense.

On what ground the alleged magnetic phenomena are to be explained is another and more delicate question : that the imagination is a powerful and important factor is beyond doubt; and when, as is generally the case, morbidly sensitive patients, especially hysterical girls, are experimented upon, the merest trace of a suggestion, unconsciously given, of the desired or expected effect, is enough to bring about all the phenomena of 'transport,' etc., for which the magnet has been held accountable. Only when tested under 
rigid and scientifically controllable conditions can the evidence of such abnormal sensibility be relied upon. Even the precautions against indications as above described would probably have to be added to, if hypnotic subjects were experimented upon.

In conclusion it is desired to lay stress not only on the negative character of the results, but on the method employed, and especially on the fact, that, as the precautions were rendered more and more effective, the negative character of the conclusions became more and more evident. ${ }^{1}$

JOSEPH JASTROW.

\section{LONDON LETTER.}

No more interesting and valuable report has been presented to parliament during the recent session than that of the inspectors of explosives for 1885. Colonel Majendie and his colleagues have been engaged for ten years in protecting the public against the most terrible dangers to which modern science has exposed it. A list of twentynine men is given who have been caught and punished for complicity in what are usually known as dynamite outrages. In 1885, 133 ordinary explosions due to accident came under the notice of the Home office, and some almost incredible stories are told of carelessness in connection with explosives. The explosion of tablets of chlorate of potash in the pocket of a gentleman in Brookline, Mass., who dropped his watch upon them quickly, is characterized as the most curious explosion of the year. Among other 'explosive medicines' is mentioned nitro-glycerine, which is made up with lozenges, etc., for use in cases of angina pectoris and other complaints. In the United Kingdom, 22,268 houses are registered for the keeping of explosives. It is the duty of the local authorities to see that the provisions of the act are complied with. Sometimes, however, they are very remiss, and the inspectors act as a useful check upon them. In 1885, 392 places where explosives were kept for retail sale were inspected, and in some cases they were found to be 'about as bad as they could be.' London, Liverpool, Bristol, Birmingham, Sheffield, Huddersfield, and Bath are selected for special commendation in this respect.

At the last meeting of the London section of the Society of chemical industry, a very valuable paper was read by Dr. Meymolt Tidy on the chemical treatment of sewage. Premising that

1 The above is simply a general account of the experiments. For a detailed account, the reader is referred to the full paper on the subject, to appear in the next number of the Proceedings of the American society for psychical research. he had for many years read every thing he could get hold of on the subject, and had also gained practical personal experience therein, he defined sewage as " the refuse of communities, their habitations, streets, and factories." Its very complex nature was commented upon. Two elements were constant, and ' the rest nowhere:' viz., $1^{\circ}$, excreta (every thousand people gave, on a very large average, 2,640 pounds of liquid, and 141 pounds of dry, sewage daily); $2^{\circ}$, roads (if woodpaving be excluded, road-washings contained, on an average, 280 grains of solid matter per gallon, of which 120 were in solution). The extreme difficulty of obtaining fair samples was amusingly commented on; and the salutary effects on sewage, of air and of dilution, as shown by the appearance therein, or otherwise, of comparatively high forms of microscopic life, such as the Vorticella, Rotifera, etc., was pointed out. An unfailing characteristic of sewage was the presence of hairs of wheat, and of free spiral cells, their casing having been dissolved in digestive processes. Authorities were agreed upon two points ; viz., that the valuable matters were in solution, and the offensive in suspension. Irrigation could not be relied on for giving absolutely continuous purity. Of the precipitation processes, those in which lime and alumina were employed successively, gave the best general results; and the smell still remaining might be entirely got rid of by causing the effluent to flow over a little land. This combination was probably the best method of dealing with liquid sewage ; but, in Dr. Tidy's opinion, the whole system of water-carriage of sewage was a mistake. It was absurd to take expensive and elaborate precautions about purity of water-supply, and then only to use one-ninetieth of this for drinking, allowing the rest to be polluted. The dry-earth system of dealing with human excreta was the only proper and scientific method.

The second, and ladies', conversazione of the Royal society was held on the evening of June 9. Many of the objects of interest exhibited at the former one were on view again. Among the novelties were the following: some microscopic sections, diagrams, and specimens illustrating the alteration artificially produced in vitreous rocks by the action of heat alone, by Mr. F. Rutley ; floral studies in Chili, of orchids, nests, etc., by Miss North; illustrative diagrams of and specimens from Roraima; some rare earths from Samarskite, Gadolinite, etc., with illustrations of their phosphorescent spectra, by Mr. W. Crookes; pumice, volcanic ash, drawings, diagrams, etc., illustrative of the great volcanic eruption, by the Krakatoa committee of the Royal society; ap- 